\title{
Analisis Gaya Kepemimpinan Kepala Perpustakaan (Studi Kasus Perpustakaan Grahatama Pustaka Yogyakarta)
}

\section{Nurfadlliah}

UIN Sunan Kalijaga Yogyakarta

nfadlliah92@gmail.com

\section{Abstrak}

Pemimpin merupakan orang yang sangat berpengaruh di lembaga organisasi. Perpustakaan juga termasuk organisasi yang membutuhkan pemimpin yang mengatur alur kerja perpustakaan. Perpustakaan Grahatama Pustaka Yogyakarta merupakan salah satu perpustakaan umum kota yang dipimpin oleh seorang kepala perpustakaan. Tulisan ini menganalisis gaya kepemimpinan Perpustakaan Grahatama Pustaka dengan menggunakan metode penelitian kualitatif. Hasil dari penelitian ini menjukakkan bahwa pimpinan grahatama termasuk kedalam pemimpin yang suprotif, partisipatif, dan berorintasi pada prestasi.

\author{
Kata kunci: \\ gaya kepemimpinan \\ perpustakaan Grhatama Pustaka.
}

\section{Pendahuluan}

\subsection{Latar Belakang}

Setiap organisasi membutuhkan pemimpin dalam menjalankan tugas organisasinya agar terstruktur dan bisa mencapai tujuan yang diinginkan organisasi. Kepemimpinan menurut umam (2010), merupakan kekusaan yang bisa mempengaruhi orang lain untuk mengerjakan sesuatu atau tidak mengejakan sesuatu. Sehingga pemimpin harus bisa bergerak aktif mepengaruhi bawahannya untuk melakukan sesuatu demi mencapai tujuan organisasi. Termasuk di dalam perpustakaan juga membutuhkan kepemimpinan untuk mencapai tujuan perpustakaan seperti apa yang diharapkan.

Perpustakaan merupakan salah satu organisasi yang dibentuk untuk melayani masyarakat luas. Untuk mencapai tujuannya maka perpustakaan membutuhkan pemimpin yang berkompeten yang bisa membawa seluruh bawahannya agar mampu bekerjasama dengan baik. Perilaku setiap orang tentunya berbeda- beda, termasuk juga seorang pemimpin juga memiliki perilaku tertentu dan gaya tertentu dalam memimpin perpustakaan. Gaya kepemimpinan ini masing-masing ada kelebihan dan kekurangan. Menurut Wijiya (2011), dalam melaksanakan kepemimpinan akan menunjukan kegiatan seorang pemimpin dalam membimbing, mempengaruhi, mengendalikan pikiran, dan tingkah laku orang lain yang dipimpinnya. Secara praktis fungsi kepemimpinan ini berbeda- beda tergantung situasi dan kondisi yang dialami seseorang, fungsi seorang pemimpin ini bisa dilihat dari orang yang dipimpinnya.

Perpustakaan Grahatama Pustaka merupakan salah satu perpustakaan umum terbesar di Yogyakarta. Penulis tertarik untuk untuk melihat gaya kepemimpinan seperti apa yang diterapkan dalam perpustakaan ini. Dari hasil wawancara dengan salah satu staff Perpustakaan Grahatama Pustaka Mbak Sri, penulis mendapatkan informasi bahwa pimpinannya merupakan orang yang ramah dengan para bawahnnya, pimpinan juga memperlakukan semua stafnya sama satu dan lainnya. Dengan pernyataan ini penulis ingin menganalisis gaya kepemimpinan yang ada di perpustakaan Grahatama Perpustakaan Yogyakarta menggunakan teori path goal, yang salah satunya juga membahas tentang keramahan (prilaku suportif) kepada bawahannya. Selain itu dengan menggunakan teori path goal penulis juga akan menganilisis gaya kepemimpinan lainnya yang 
diterapkana di Perpustakaan Grahatama Pustaka Yogyakarta.

\section{Landasan teori}

Adapun yang menjadi landasan teori dalam tulisan ini adalah pengertian perpustakaan umum, kepemimpinan, dan gaya kepemimpinan.

\subsection{Perpustakaan Umum}

Menururt Sutarno (2006), pengertian perpustakaan secara umum merupakan ruangan yang menyediakan koleksi yang disusun secara rapi sehingga pemustaka mudah dalam melakukan temu kembali informasi. Teori ini menyatakan bahwa perpustakaan merupakan suatu ruangan atau gedung yang berisikan informasi baik cetak dan noncetak yang disusun secara rapi sehingga temu kembali informasi oleh pemustaka semakin mudah. Perpustakaan umum menurut Sutarno (2006), merupakan lembaga umum bagi masyarakat luas yang menyediakan informasi, ilmu pengetahuan, perkembangan teknologi dan kebudayaan yang digunakan oleh masyarakat umum sebagai sumber belejar.

Perpustakaan Grahatama Pustaka Yogyakarta merupakan salah satu perpustakaan yang menyediakan informasi untuk semua lapisan masyarakat Yogyakarta. Di dalam perpustakaan ini terdapat banyak ilmu pengetahuan dan teknologi informasi yang digunakan untuk memenuhi kebutuhana informasi masyarakat. Untuk mencapai tujuan perpustakaan Grhatama yang ideal tentunya harus ada kerjasama yang baik antara pimpinan dan staff agar tecipta lingkungan kerja perpustakaan yang disenangi oleh masyarakat umum yang berkunjung ke perpustakaan Grahatama.

\subsection{Pengertian Kepemimpinan}

Menurut Mullins \& Linehan (2005), kepemimpinan merupakan faktor yang paling penting dari faktor yang lainnya dalam keberhasilan sebuah organisasi. Organisasi yang bagus tentunya dipimpin oleh seorang yang bagus pula dalam memimpin organisasinya. Termasuk dalam sebuah perpustakaan juga membutuhkan sosok pemimpin yang bisa mengatur jalannya organisasi perpustakaan ini untuk mencapai tujuannya. Pemimpin inilah yang nantinya akan mengatur kerja staff perpustakaan, untuk mengambil keputusan terbaik dalam menjalankan tugasnya.

Pemimpin merupakan orang yang cerdas mental dan intelektualnya serta pandai menentukan sikap yang harus diambil dalam mengatur sebuah organisasi untuk melakukan perubahan sosial yang mendasar guna mencapai tujuan yang didambakan rakyat (Rasim, 2014). Jika dikaitkan dengan perpustakaan maka seorang pemimpin perpustakaan adalah orang yang kuat mental dan intelektualnya, untuk membuat perubahan sosial dalam lingkungan perpustakaan yang berguna untuk mecapai tujuan perpustakaan.

Seorang pemimpilah yang nantinya akan menentukan kemajuan suatu perpustakaan. Pemimpina dituntut menjadi orang yang mempelopori terjadinya perubahan sosial didalam masyarakat. Perubahan sosial inilah yang nantinya bisa dijadikan sebagai alat untuk mencapai tujuan organisasi perpustakaan.

\subsection{Gaya kepemimpinan}

Setiap orang yang memimpin tentunya tidak selalu mempunyai gaya yang sama, karena seseorang mempunyai sifat yang berbeda satu dengan lainnya. Termasuk didalam memimpin perpustakaan tentunya setiap pemimpin mempunyai gaya tersendiri untuk diterapkan sesuai dengan background organisasi yang dipimpinnya. Adapun gaya kepemimpinan menurut Kreitner \& Kinicki (2000), adalah pimpinan yang selalu memberikan nasihat, bimbingan, inspirasi, dan motivasi, menyelesiakan konflik, dalam membangun kelompok organisasi. Yang tujuana untuk membuat perubahan yang transformatif dikalangan organisasi yang dipimpinnya.

Kepemimpina berkaitan erat dengan gaya kepemimpinan, dan situasi yang sedang terjadi 
disekitar tempat yang dipimpinnya. Menurut Yulk (2006), bahwa kepemimpinan yang efektif dipengaruhi oleh beberapa faktor diantaranya faktor:

\section{Karakteristik pemimpin}

Karakteristik pemimpin meliputi motivasi, keperibadian yang baik, nilai, keyakinan, optimisme, keterampilan, keahlian, integritas dalam etika, taktik, dan sifat dari pengikutnya.

3. Karakteristik pengikut

Adapun yang menjadi ciri karakteristik pengikut adalah kebutuhan, nilai, konsep diri, kayakinan, optimisme, keahlian, keterampilan, sifat dari pemimpinnya, kepercayaan kepada pemimpin, komitmen, kepuasan terhadap pemimpin dan pekerjaan yang dilakukannya.

4. Karakteristik organisasi

Termasuk di dalammnya jenis organisasi, besar atau tidaknnya organisasi, wewenang, kerumitan tugas dan struktur, ketergantungan eksternal, dan keadaan lingkungan yang sering berubah.

Tiga hal inilah yang nantinya mempengaruhi keefektifitasan dalam sebuah kepemimpinan. Jika dari ketiga hal diatas saling besinergi tentunya akan terciptalah kepemimpinan yang bagus. Sedangkan menurut Haouse dalam Robbin (2009), menjelaskan ada empat perilaku pemimpin yang dikenal dengan teori path goal, penjelasannya sebagai berikut;

1. Perilaku derektif (pengarah)

Merupakan perilaku yang menunjukkan dominasi pemimpin kepada bawahan mulai dari mengarahkan, mengawasi, dan mengatur bawahan. Pemimpin model ini akan menekankan bawahan untuk mengikuti aturan organisasi yang telah berlaku.

2. Perilaku suportif

Merupakan perilaku pimpinan yang membuat bawahan sebagai rekan kerja yang asik. Pemimpin suportif selalu memberikan perhatian besar terhadap kesejahteraan bawahannya. Tipikel pemimpin ini sangat bersahabat dengan bawahan dan dapat didekati dengan mudah. Karena pemimpin yang berprilaku suportif selalu ramah dengan bawahannya.

\section{Perilaku partisipatif}

Merupakan perilaku pemimpin yang selalu berdiskusi kepada bawahan sebelum membuat sebuah keputusan organisasi.

\section{Perilaku yang berorentasi pada prestasi}

Merupakan perilaku pemimpin yang mempunyai tujuan yang jelas dalam melakukan kerja organisasi, serta mempunyai tantangan yang besar bagi bawahannya untuk berprestasi.

Setiap pemimpin tentutnya memiliki perilaku tertentu dalam memimpin bawahannya. Pemimpin yang baik adalah pemimpin yang bisa menempatkan perilakunya sesuai dengan situasi dan kondisi organisasi yang dipimpinnya.

\section{Metode Penelitian}

Dalam tulisan ini metode yang digunakan adalah metode kualitatif. Metode kualitif merupakan metode yang berusaha memahami dan menafsirkan makna baik itu peristiwa, interaksi manusia, dalam situasi dan kondisi tertentu. Penelitian kualitatif ini bertujuan untuk memhami objek yang diteliti secara mendalam. Menurut Strust dan Corbin dalam Cresswell J (1998), penelitian kualitatif ini adalah penelitian yang tidak bisa dicapai dengan menggunakan cara pengukuran (kuantitaf). Adapun hal yang diteliti dalam penelitian kualitatif mengenai kehidupan masyarakat, sejarah, tingkah laku, fungsional organisasi, dan aktivitas manusia lainnya.

Dalam penelitian gaya kepemimpina perpustakaan Grahatama Pustaka ini penulis menggunakan metode kualitatif untuk mendeskripsikan gaya kepemimpinan yang ada di perpustakaan tersebut. Dalam hal ini penulis melakukan wawancara kepada dua orang informan yang merupakana staaff Perpustakaan 
Grahatama Pustaka. Wawancara ini tujuannya untuk mendapatkan gaya kepimpinan Grahatama termasuk kedalam gaya prilaku apa dengan menggunakan teori path goal saat memimpin bawahannya.

\section{Pembahasan}

Untukmelihat gaya kepemimpinan Perpustakaan Grahatama Pustaka Yogyakarta, penulis menggunakan teori path goal yang menjelaskan empat perilaku pemimpin, (1) pemimpin yang berperilaku derektif atau pengarah, (2) pemimpin yang berperilaku suportif, (3) pemimpin yang berperilaku partisipatif, (4) pemimpin yang berorentasi pada prestasi.

\subsection{Pemimpin yang berprilaku derektif atau pengarah}

Berdasarkan informasi yang didapatkan dari beberapa informan menyatakan bahwa pemimpin Grahatama Pustaka bukanlah termasuk pada pemimpin yang selalu mengarahkan bawahannya secara mendetail. Pemimpin hanya menjelaskan kepada bawahannya, bagaimana caranya untuk melayani pemustaka yang datang dengan baik. Pernyataan ini berdasrkan dari penyataan informan pertama sebagai berikut:

"pimpinan kami sih tidak mengarahkan tugas kami di perpustakaan secara mendetail mbak, beliau hanya menjelaskan beberapa poin saja, beliau hanya mengarahkan bawahannya bagaiaman caranya melayani pemustaka yang datang ke perpustakaan dengan baik".

Infoman kedua juga menambahkan informasi bahwa pimpinan Grahatama memang tidak menjelaskan secara detail tentang tugas yang harus dilaksanakan di perpustakaan. Adapun pernyataan informan kedua sebagai berikut:

"kami tidak pernah mendapatkan arahan yang sangat detail dari pimpinan mbak, tapi sayajuga gg tau bagian yang lain diarahkan sangat detail atau sama saja dengan kami tidak diarahkan langsung. Akan tetapi kepala bagian kami yang mengarahkan, kalo dari pimpinan tidak ada pengarahan langsung, mungkin pimpinan mengarahkan kepala kami kemudian kepala kami yang melakukan pengarahan dengan kami".

Dari pernyataan dua infroman diatas dapat disimpulkan bahwa pimpinan Perpustakaan Grahatama Pustaka merupakan pemimpin yang tidak terlalu mengarahkan tugas bawahannya secara detail. Pimpinan Grahatama hanya menjelaskan mengenai pelayan kepada pemustaka saja. Pimpinan Grahatama lebih banyak mengarahkan kepala bagian masing-masing bidang. Kemudian bawahannya akan mendapatkan detail pekerjaan dari kepala masing-masing bidang ini.

\subsection{Pimpinan yang berperilaku suportif}

Dari hasil wawancara dengan informan pertama menyatakan bahwa pimpinan Perpustakaan Grahatama merupakan pemimpinan yang selalu berperilaku mensupor bawahannya, berperilaku ramah, dan mengevaluasi kinerja bawahannya. Adapun pernyataan informan pertama sebagai berikut:

"beliau orangnnya selalu memberikan motivasi kepada kami agar bekerja lebih baik mb, agar saat mengikuti kegiatan didalam maupun diluar perpustakaan menunjukkan kulitas kerja yang baik. Selian itu beliau juga selalu menyapa kami saat berpapasan, dan setiap dua bulan sekali juga mengevaluasi kerja kami"

Hal senada juga disampaikan oleh infoman kedua bahwa pimpinan Grahatama Pustakawa merupakan orang memberikan dukungan kepada bawahannya, memberikan motifasi saat evaluasi berlangsung, dan selalu bersikap ramah. Pernyataan informan kedua sebagai berikut:

"Pimpinan kami termasuk orang yang sangat ramah sama kami mbak, beliau juga sering memberikan motivasi kerja kepada kami saat rapat evaluasi bulanan tujuan dari evaluasi ini agar kami bisa memperbaiki kualitas kerja kami 
mbak, dan pemustaka yang datangpun puas dengan layanan yang kami berikan".

Dari penjelasan kedua informan diatas, dapat disimpulkan bahwa pimpinana Grahatama Pustaka merupakan orang yang selalu mendukung bawahannya dari berbagai hal. Mulai dari sikapnnya yang ramah kepada bawahan, dan memberikan motivasi kerja ke bawahan setiap evaluasi rapat kerja dua bulan sekali.

\subsection{Pimpinan yang berperilaku partisipatif}

Berdasarkan informasi dari informan pertama, menyatakan bahwa pimpinan Grahatama Pustaka termasuk orang yang partisipatif dalam mengambil keputusan. Hal ini sesuai dengan pernyataan informan pertama sebagai berikut:

"Kalo pimpinan kami mbak, dalam mengambil keputusan selalu melibatkan kami. Selain itu beliau juga memberikan respon yang baik terhadap ide dan saran dari kami".

Informan kedua menyatakan hal yang sama bahwa pimpinan Grahatama merupakan orang yang selalu melibatkan bawahannya dalam mengambil keputusan. Pernyataan informan kedua sebagai berikut:

"Beliau itu orangnya enak mbak selalu melibatkan kami selaku bawahannya dalam berbagai hal, gg pandang bulu gitu."

Dari pernyataan kedua informan di atas dapat disimpulkan bahwa pimpinan Grahatama Pustaka termsuk orang yang partisipatif dengan bawahannya. Bawahannya selalu dilibatkan dalam pengambilan keputusan.

\subsection{Pimpinan yang berorintasi pada prestasi}

Pimpinan Grahatama termasuk orang yang berorintasi kepada prestasi hal ini sesuai dengan pernyataan informan pertama yang menyatakan bahwa pimpinan sering menyuruh kami untuk ikut event yang ada di daerah maupun tingkat nasional, mulai dari menulis maupun kegiatan seminar. Adapun pernyataan informan pertama sebagai berikut:
"Pimpinan kami selalu memberikan motivasi samakamimbak, nyuruhikutlombapenulisanlah, terus disuruh ikut kegiatan perpustakaan seperti seminat gitu, kadang - kadang kegiatannya ada didalam kota kadang juga sampai nasional, kata beliau agar pengalaman kami bertambah".

Hal senada juga disampaika oleh informan kedua yang menyatakan bahwa pimpinan Grahatama berorintasi kepada prestasi. Bahkan saat ulang tahun Grahatama dibuat kegiatan lomba untuk pustakawan, agar termotivasi nantinya dari ikut lomba di dalam perpustakaan kemudian akan ikut lomba di daerah maupun tingkat nasional. Penyataan informan kedua sebagai berikut;

"Beliau selalu memotivasi kami mbak mulai dari disuruh ikut lomba didalam perpustakaan saat perayaan ulang tahun, yang nantinya akan menumbuhkan keterampilan kami untuk bersaing mengikuti event perpustakaan baik didaerah maupun tingkat nasional"

Dari pernyataan kedua informan tersebut sudah jelaslah bahwa pimpinan perpustakaan Grahatama merupakan tipikal pemimpin yang berorintasi kepada prestasi dengan cara memotivasi bawahannya untuk ikut berbagai kegiatan perpustakaan, baik lomba maupuan kegiatan seminar.

\section{Simpulan}

Berdasarkan analisis yang didapatkan dari informan dapat disimpulkan bahwa kepemimpinan yang diterapkan di Perpustakaan Grahatama Pustaka merupakan gaya kepemimpinan yang pengarah, suportif, partisipatif, dan berorintasi pada prestasi. Hal ini terlihat dari motivasi yang sering pimpinan berikan kepada staffnya. Bawahannya selalu dilibatkan dalam mengambil keputusan, intinya melakukan musyawarah terlebih dahulu sebelum mengambil keputusan. Selain itu pimpinan Grahatama selalu mengajak bawahannya untuk mengikuti lomba baik di tingkat daerah maupun nasional. Untuk perilaku yang mengarahkan, 
pimpinan Grahatama tidak mengarahkan secara detail mengenai arahan kerja kepada semua bawahannya. Akan tetapi pimpinan mengarahkan kepala bidang, kemudian dari kepala bidang ini yang akan mengarahkan secara detail mengenai arahan kerja ke staff masing - masing.

\section{Daftar Pustaka}

Cressweel, J. Resecrch Design : Qualitative \& Quantitative Approaches.

Thousand oaks, CA, Sage Publication. 1998.

Kreitner, Robert and A. Kinicki. Organizational Behavior, New York: McGraw-Hill Companies, Inc, 2000 \& 2008.

Mullins, J., \& Linehan, M. The central role of leaders in public libraries. Library Management. 2005.

Rasim, Ahmad. "Tipologi dan Karakter Ideal Kepemimpinan Dunia". Jurnal

Lingkar Widiaswara, Edisi 1, No 1, 2014. Dalam "setting" http://juliwi.com/published/E0101/ Paper0101_46-52.pdf , 5 Januari 2018.

Robbins S. P. \& Timothy A. Judge, Organizatonal Behavior, New York: Upper Saddle River. 2009.

Sutarno Ns, Perpsustakaan dan Masyarakat. Jakarta: Sagung Seto. 2006.

Umam, khaerul . Perilaku Organisasi. Bandung: Pustaka Setia. 2010.

Wijaya, Muksin. "Kepemimpinan Transformasional di Sekolah Dalam

Meningkatkan Outcomes Peserta Didik". Jurnal Pendidikan Vol 2, 2011.

Yukl, G. Leadership in organizations (6th ed.). Upper Saddle River, NJ: Prentice Hall. 2006. 